\title{
Transition to new technologies of rice cultivation in the Krasnodar Territory
}

\author{
Igor Prikhodko ${ }^{1 *}$, Stanislav Vladimirov ${ }^{1}$, and Daniel Alexandrov ${ }^{1}$ \\ ${ }^{1}$ Kuban State Agrarian University named after I.T. Trubilin, st. Kalinina, 13, Krasnodar, 350044, \\ Russia
}

\begin{abstract}
Currently used in Russia traditional technologies of rice cultivation with continuous or short-term flooding of rice paddies are ineffective for a number of factors, the main of which are the high cost and high labor intensity of rice production. Research in the field of rice cultivation has identified four main promising technologies that can reduce the cost of rice produced: 1 - intermittent flooding; 2 - periodic moistening without creating a layer of water; 3 - sprinkling, including surface irrigation; 4 - drip irrigation. The purpose of our research was to develop a new drip irrigation rice cultivation technology adapted for the climatic and soil conditions of the Krasnodar Territory. As a result of the research carried out, a drip irrigation technological scheme was developed and implemented for LLC "Chernoerkovskoye" of the Slavyansky district of the Krasnodar region. The developed scheme of rice cultivation on drip irrigation has proven its effectiveness, expressed in improving the reclamation state of soils, increasing the profitability of production and increasing the yield, reducing the irrigation rate, the cost of rice grain and labor intensity.
\end{abstract}

\section{Introduction}

Numerous foreign and domestic studies of the cultivation of both dry and aerobic rice show [1-8] that the issue of transition from flooded rice to aerobic rice is relevant and should be worked out in accordance with all modern ecological and reclamation requirements that are currently imposed on production agricultural products, including rice culture $[9,12]$. High interest among rice producers, as a rule, is associated with the further impossibility and/or inefficiency of rice production using the traditional technology of rice cultivation with continuous or shortened flooding of rice paddies due to the lack or insufficiency of the required volume and / or quality of irrigation water, lack of the necessary technical support for the implementation of all agrotechnical methods necessary for the normal cultivation of rice, reducing the soil reclamation state to a level at which the introduction of organic and mineral fertilizers does not compensate for the low soil fertility and is ineffective and economically inexpedient [13-16]. On the rice irrigation systems of the Lower Kuban, the main subtypes of rice soils are meadow chernozem, meadow, alluvial meadow-boggy (heavy merged chernozems). Since the beginning of their use for rice sowing, a stable

* Corresponding author : prihodkoigor2012@yandex.ru 
tendency towards a decrease in favorable physical properties has been noted [17-18]. The soils become degraded, merged, viscous, gleyed formations, on which low-volume surface sprinkling, and even more so flooding, is ineffective. Long-term practice of rice cultivation on rice irrigation systems of the Krasnodar Territory revealed the urgent problem of a high degree of weed infestation in rice paddies, which in turn requires high expenditures of financial and labor resources to obtain planned yields without reducing the reclamation state of soils [19-20]. At the same time, the world practice of cultivation of agricultural crops has accumulated sufficient experience in the implementation of resource-and-energysaving technologies of drip irrigation, ensuring profitable crop cultivation [21]. Considering all of the above, it becomes obvious the relevance of research on optimization of methods of rice cultivation based on drip irrigation under polyethylene and / or mulching perforated film in relation to the conditions of the Krasnodar Territory.

\section{Materials and methods}

The developed method of rice cultivation includes growing rice on the lands of the irrigated rice fund on drip irrigation under plastic and/or biodegradable perforated film.

In the fall, in the first year of rice cultivation, after harvesting the predecessor, one-time production of:

- cutting and restoration of peripheral check grooves with a depth of 0.4-0.6 m;

- alignment of the surface of receipts;

- basic tillage to a depth of $0.22-0.25 \mathrm{~m}$;

- cleaning of irrigation and waste canals;

- filling of check rollers up to design marks;

- deep loosening (chiseling) to a depth of 0.16-0.18 m;

- disking with incorporation of organic fertilizers to a depth of $0.10-0.12 \mathrm{~m}$ with an application rate of 40-50 tons per hectare of manure or green fertilizer.

In the spring of the first year of implementation of the method:

- harrowing with tooth harrows in two tracks to a depth of $0.08 \mathrm{~m}$,

- the formation of ridges by making depressions in the form of inter-ridge technological passages and passages, which are covered with non-woven geosynthetic material, while the size and distance between the ridges depend on the technical characteristics of the technique used for cultivating rice and related crops of rice crop rotation.

Then the annual spring-autumn technological cycle of work is carried out, including:

- restoration of the geometry of ridges;

- rolling the soil of the ridges;

- assembly of a drip irrigation system, including a fertigation system;

- laying of drip tapes (Figures 1-3) with a step between outlets $-20 \mathrm{~cm}$, diameter and wall thickness of the drip tape - $16 \mathrm{~mm}$ and $0.2 \mathrm{~mm}$, respectively, and the water outflow of the drip tape in $1 / \mathrm{h}$ per $1 \mathrm{~m}$ is taken from the provision in during the growing season of rice, soil moisture is $80 \%$ of $\mathrm{HB}$ in a layer of $0.4 \mathrm{~m}$, as well as the required moisture in a given soil layer for rice crop rotation, moreover, the distance between drip tapes is $24 \mathrm{~cm}$, and it is laid on the ridges in compliance with the irrigation conditions of one drip tape of two rows of perforations on a mulching film, with a perforation diameter of $6 \mathrm{~cm}$, the distance between which in a row and between adjacent rows is $6 \mathrm{~cm}$ each;

- pre-planting watering before planting rice with an irrigation rate providing soil moisture of $90 \%$ of $\mathrm{HB}$ in a layer of $0.6 \mathrm{~m}$;

- soil surface treatment with soil herbicides;

- covering the ridges with perforated mulch film;

- growing rice seedlings in nutrient pots, in a substrate of various components, 
namely, highly fertile field land, sod land, humus, high peat, coarse sand, while the humus content in the substrate should be at least $40 \%$, the substrate density is less than one, the porosity - 60-90\%, air content - not less than $10 \%$;

- adding trace elements to the substrate before planting rice seeds $\mathrm{N}_{80} \mathrm{P}_{120} \mathrm{~K}_{60}$ in $\mathrm{kg}$ a.d./ha;

- maintaining a round-the-clock temperature regime during the entire period of growing rice seedlings: during the day $20-24^{\circ} \mathrm{C}$, in cloudy weather $-16-18^{\circ} \mathrm{C}$, at night $15-16^{\circ} \mathrm{C}$

- maintaining the optimum pre-irrigation moisture content of the substrate at a level of $55-65 \%$ of $\mathrm{HB}$ during the entire period of growing rice seedlings;

- maintaining a relative humidity of $60-70 \%$ during the entire period of growing rice seedlings;

- maintaining illumination for at least 14-16 hours a day during the entire period of growing rice seedlings;

- - feeding rice seedlings in the phase of 2-3 leaves with nitrogen fertilizers in dissolved form at the rate $\mathrm{N}_{40}$ in $\mathrm{kg}$ a.d./ha;

- spraying 1-2 days before planting rice seedlings in open ground with biologically active substances;

- planting rice seedlings in the amount of 1 to 3 rice plants in one perforation of the mulching film in the phase of 6-7 leaves, while it should be with a pronounced green color, well-developed root system, not infected with pests and diseases;

- introduction by the fertigation method through the drip irrigation system of microelements (N: P: K) with the norm depending on the agrophone and carried out in several stages, namely in the phase of 8-9 leaves after the complete survival of rice seedlings and in the tillering phase of rice;

- drip irrigation of rice plants through a drip irrigation system during the growing season with the frequency and rate of irrigation depending on compliance with the condition for ensuring constant soil moisture of $80 \%$ of HB in a layer of $0.4 \mathrm{~m}$;

- treatment of rice with herbicides in the phase of 3-4 leaves;

- rice treatment with fungicides in the tube exit phase;

- rice harvesting.

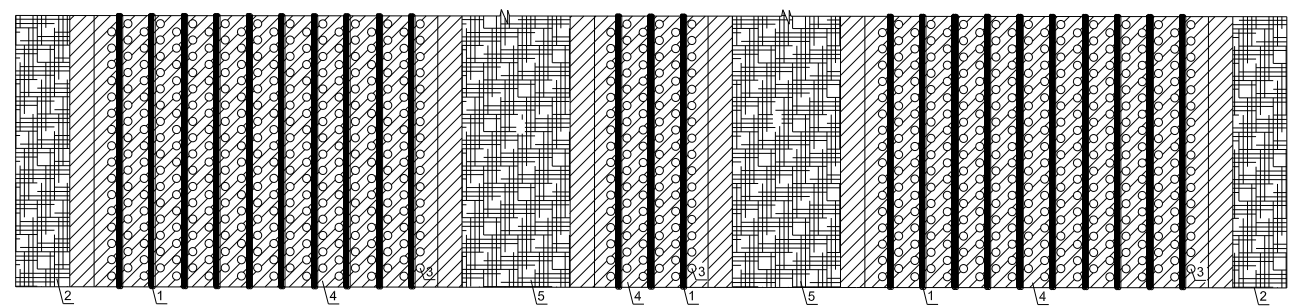

Fig. 1. Technological scheme of one capture on the example of using the Don 1500 combine when growing rice on drip irrigation with laying a drip tape on the soil surface under a mulching film, including biodegradable. 1 - drip tube; 2 - technological passage; 3 - round perforation in mulch film for planting crops; 4 - mulch film; 5 - tramline for agricultural machinery. 


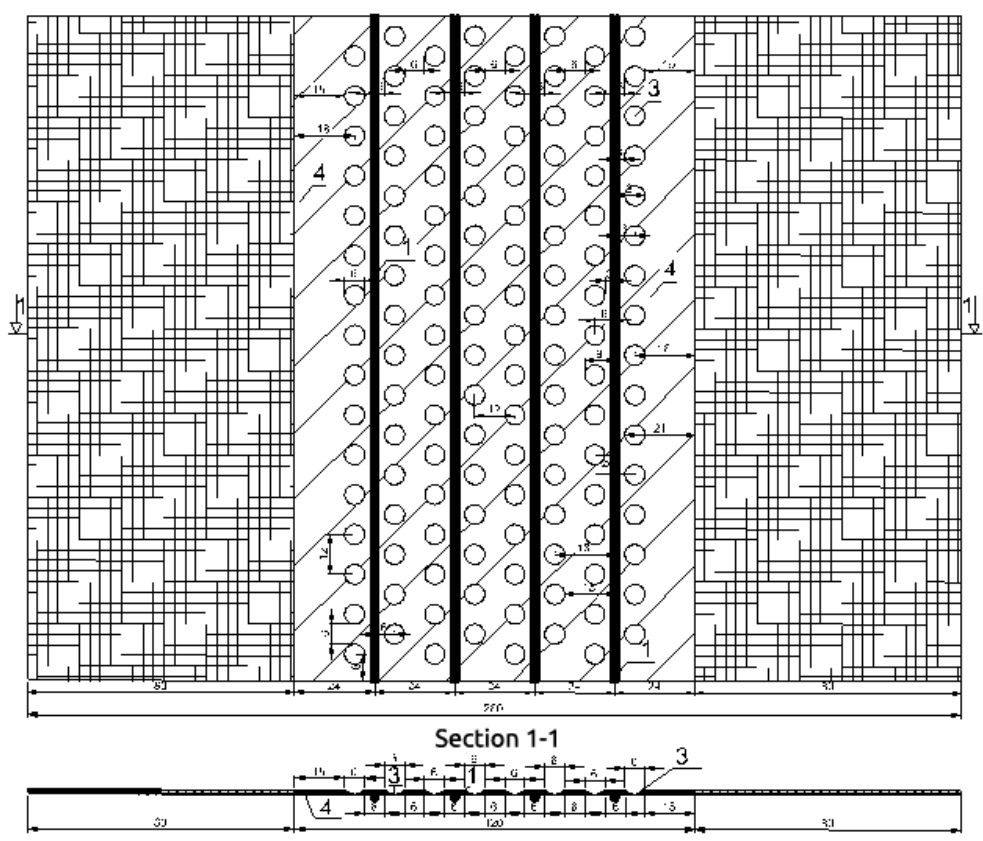

Fig. 2. Fragment of the central part of the technological scheme of one capture during the cultivation of rice on drip irrigation with the laying of a drip tape on the soil surface under a mulching film, including biodegradable. 1 - drip tube; 2 - technological pass; 3 - round perforation in mulch film for planting crops; 4 - mulch film; 5 - tramline for agricultural machinery.

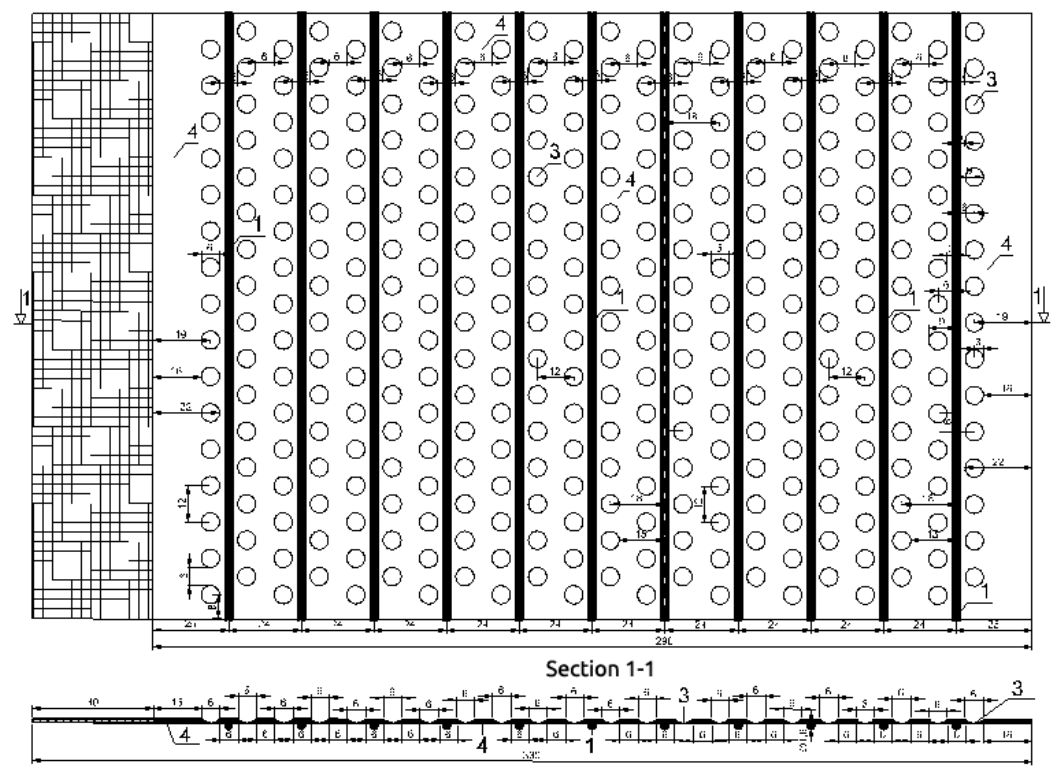

Fig. 3. Fragment of the left part of the technological scheme of one capture during the cultivation of rice on drip irrigation with the laying of a drip tape on the soil surface under a mulching film, including biodegradable. 1 - drip tube; 2 - technological pass; 3 - round perforation in mulch film for planting crops; 4 - mulch film; 5 - tramline for agricultural machinery. 
The rice cultivation scheme shown in Fig. 1-3 is a particular example for use on the farm, taking into account its technological support. Consequently, the proposed technology has an optimization-adaptive multi-level structure that allows using not only the technological support of a particular farm under consideration, but also other resources of the farm (ecological reclamation, energy, economic, breeding, labor) for the development of complex management decisions on the preparation of a technological map and ecological -economic and reclamation balanced crop rotation, which will allow not only to receive the programmed yields of rice and rice crop rotation, but also to preserve the existing ecosystem.

\section{Results and its discussion}

As a result of approbation of the method of rice cultivation with drip irrigation under mulching perforated film in OOO Chernoerkovskoye, Slavyansky district, with an area of 4.5 hectares for 2016-2019, it was possible to prove the efficiency of rice cultivation (Table 1).

Table 1. Biometric and quantitative characteristics of rice.

\begin{tabular}{|c|c|c|c|c|c|}
\hline \multirow{2}{*}{$№$} & \multicolumn{4}{|c|}{ Years } \\
\cline { 3 - 6 } & Name & 2016 & 2017 & 2018 & 2019 \\
\hline 1 & Vegetation period & 117 & 119 & 118 & 120 \\
\hline 2 & Panicle height, cm & 90,4 & 90,8 & 91,4 & 91,2 \\
\hline 3 & Panicle length, cm & 17,6 & 18,3 & 18,8 & 18,9 \\
\hline 4 & Number of grains, pcs.: & 204 & 208 & 210 & 215 \\
\hline \multirow{2}{*}{5} & - general & 75 & 77 & 79 & 82 \\
& - empty & 2 & 2 & 1 & 1 \\
\hline 6 & Emptyness, \% & 2,6 & 2,2 & 1,8 & 1,5 \\
\hline 7 & The number of spikelets in a panicle, pcs. & 1,9 & 2,0 & 2,1 & 2,2 \\
\hline \multirow{3}{*}{8} & Caryopsis length to width ratio (1/b) & 2,5 & 2,6 & 2,6 & 2,6 \\
& - grain & 2,3 & 2,3 & 2,3 & 2,4 \\
\hline 9 & - straw & 0,92 & 0,88 & 0,88 & 0,92 \\
\hline 10 & Straw: grain ratio & 28 & 27 & 29 & 30 \\
\hline 11 & Weight of 1000 grains, g & 11,3 & 11,6 & 12,1 & 13,4 \\
\hline 12 & Productivity, t/ha & 10,5 & 10,7 & 10,8 & 10,5 \\
\hline \multirow{2}{*}{13} & Yield control, t/ha & 0,8 & 0,9 & 1,3 & 2,9 \\
& Increase in yield & 7,1 & 7,8 & 10,7 & 21,6 \\
\hline
\end{tabular}

Table 1 shows that the cultivation of rice on drip irrigation under polyethylene and mulching perforated film on the lands of the irrigation fund made it possible to obtain an increase in rice yield by more than $20 \%$.

The irrigation rate, on average, over the years of research was reduced by 5 times and amounted to about 3.5 thousand $\mathrm{m}^{3} / \mathrm{ha}$. The doses of pesticides and herbicides were reduced by more than $40-45 \%$. The restoration of soil structure was observed. There is practically no pollution of water intakes as a result of the application of the developed technology of rice cultivation.

This technology of rice cultivation makes it possible to develop a comprehensive multilevel system of rice cultivation in compliance with all environmental protection requirements, including the creation of fundamentally new rice crop rotations with the inclusion of, in addition to cereals and legumes, vegetables (including leafy vegetables: spinach, lettuce) and melons, which will allow not only maintaining the soil balance of 
micro and macro elements of the soil, but also the most effective use of the agro-resource potential of the region's ecosystem.

\section{Output}

As a result of the cultivation of rice on drip irrigation under polyethylene and mulching perforated film on the lands of the irrigation fund, the effectiveness of the technology of rice cultivation developed by us was proved. The developed technology is an ecologically safe farming system for rice cultivation.

The proposed technology reduces the anthropogenic load and improves the ecological and reclamation situation in the rice irrigation system. Due to the absence of the groundwater connection with irrigation water, not only the process of carrying out mineral, organic and chemical treatment of plants to the underlying layers has been stopped, but also their further movement into the water intake (rivers, lakes, estuaries), which has a beneficial effect on the environment and health person.

This technology is a "universal tool" in the creation of new technical and technological solutions to improve existing technologies for rice cultivation and the creation of new standards for the widespread use of this technology, both on the lands of the irrigation fund, and on previously dry lands. The proposed technology is a constructive step towards the implementation of government orders for the transition to environmentally friendly farming.

\section{References}

1. S. S.Girsang, T. Q. Correa Jr, J. R. Quilty, et al., Soil and Tillage Research, 202, 104647 (2020), doi.org/10.1016/j.still.2020.104647

2. G. Arbat, S. Cufí, M. Duran-Ros, J. Pinsach, et al., Water (Switzerland), 12(6), 1724 (2020)

3. I. P. Kruzhilin, M. A. Ganiev, V. V. Melikhov, et al., Water saving eco-friendly technology of rice irrigation, in Proceedings of the Conference AgroCON-2019, 012100 (2019)

4. I. P. Kruzhilin, S. D. Fomin, T. A. Gamm, A. A. Mushinskiy, Assessing the ecological state of agricultural irrigated fields of the orenburg gas processing complex with dumping sewage water for crop irrigation, in Proceedings of 2019th International Symposium on Earth Sciences: History, Contemporary Issues and Prospects, 012037 (2019)

5. I. P. Kruzhilin, A. S. Ovchinnikov, N. V. Kuznetsova, et al., ARPN Journal of Engineering and Applied Sciences, 13(13), 4181-4184 (2018)

6. I. P. Kruzhilin, M. A. Ganiev, V. V. Melikhov, et al., ARPN Journal of Engineering and Applied Sciences, 12(24), 7118-7123 (2017)

7. H. Chen, W. Zeng, Y. Jin, et al., Journal of Hydrology, 591, 125325 (2020)

8. S. M. Pabitra, Journal of Environmental Management, 279, 111620 (2021) doi.org/10.1016/j.jenvman.2020.111620

9. M. Ishfaq, N. Akbar, S. A. Anjum, M. Anwar-Ijl-Haq, Journal of Integrative Agriculture, 19(11), 2656-2673 (2020)

10. Z. Chen, P. Li, S. Jiang, H. Chen, J. Wang, C. Cao, Science of The Total Environment 757, $143748(2021)$ 
11. R. Joshia, B. Singh, A. Shukla, Current Plant Biology, 13, 45-52 (2018), doi.org/10.1016/j.cpb.2018.05.001

12. M. A. B. Pinto, J. M. B. Parfitt, L. C. Timm, et al., Field Crops Research, 248, 107714 (2020), doi.org/10.1016/j.fcr.2020.107714

13. F. Monaco, G. Sali, Agricultural Water Management, 195, 47-57 (2018)

14. T. Safronova, S. Vladimirov, I. Prikhodko, and A. Sergeyev, E3S Web of Conferences 210, 05014 (2020), doi.org/10.1051/e3sconf/202021005014

15. S. Vladimirov, T. Safronova, and I. Prikhodko, IOP Conf. Series: Materials Science and Engineering, 913, 042008 (2020), doi:10.1088/1757-899X/913/4/042008

16. S. Vladimirov, T. Safronova, and I. Prikhodko, International Agricultural Journal, 62 (4) 171-185 (2019), doi:10.24411/2588-0209-2019-10093

17. D. P. Patel, A. Dasb, G. C. Munda, et al., Agricultural Water Management, 97(9), 1269-1276 (2010), doi.org/10.1016/j.agwat.2010.02.018

18. A. López-Piñeiro, D. Peña, Á. Albarrán, et al., Journal of Environmental Management, 237, 44-53 (2019), doi.org/10.1016/j.jenvman.2019.02.058

19. P. Vijayaraghavareddy, Y. Xinyou, P. C. Struik, et al., Rice Science, 27(4), 345-354 (2020), doi.org/10.1016/j.rsci.2020.05.009

20. M. D. M. Kadiyala, J. W. Jones, R. S. Mylavarapu, et al., Agricultural Water Management, 149, 23-32 (2015), doi.org/10.1016/j.agwat.2014.10.019

21. S. F. Islam, B. O. Sander, J. R. Quilty, et al., Science of The Total Environment, 739, 140215 (2020), doi.org/10.1016/j.scitotenv.2020.140215 